Applied Remote Sensing

\title{
Vegetation greenness trend (2000 to 2009) and the climate controls in the Qinghai-Tibetan Plateau
}

Li Zhang

Huadong Guo

Lei Ji

Liping Lei

Cuizhen Wang

Dongmei Yan

Bin Li

Jing Li 


\title{
Vegetation greenness trend (2000 to 2009) and the climate controls in the Qinghai-Tibetan Plateau
}

\author{
Li Zhang, ${ }^{\text {a,b }}$ Huadong Guo, ${ }^{\text {a }}$ Lei Ji, ${ }^{\mathrm{c}}$ Liping Lei, ${ }^{\mathrm{a}}$ Cuizhen Wang, ${ }^{\mathrm{d}}$ \\ Dongmei Yan, ${ }^{a}$ Bin $\mathrm{Li}^{\mathrm{a}}{ }^{\mathrm{a}}$ and Jing $\mathrm{Li}^{\mathrm{b}}$ \\ ${ }^{\mathrm{a}}$ Chinese Academy of Sciences, Institute of Remote Sensing and Digital Earth, Key Laboratory \\ of Digital Earth Science, Beijing 100094, China \\ lizhang@ceode.ac.cn \\ ${ }^{b}$ Beijing Normal University, Academy of Disaster Reduction and Emergency Management, \\ Beijing 100875, China \\ ${ }^{c}$ ASRC Research and Technology Solutions, Sioux Falls, South Dakota 57198 \\ ${ }^{\mathrm{d}}$ University of Missouri, Department of Geography, 8 Stewart Hall, Columbia, Missouri 65211
}

\begin{abstract}
The Qinghai-Tibetan Plateau has been experiencing a distinct warming trend, and climate warming has a direct and quick impact on the alpine grassland ecosystem. We detected the greenness trend of the grasslands in the plateau using Moderate Resolution Imaging Spectroradiometer data from 2000 to 2009 . Weather station data were used to explore the climatic drivers for vegetation greenness variations. The results demonstrated that the region-wide averaged normalized difference vegetation index (NDVI) increased at a rate of $0.036 \mathrm{yr}^{-1}$. Approximately $20 \%$ of the vegetation areas, which were primarily located in the northeastern plateau, exhibited significant NDVI increase trend ( $p$-value $<0.05$ ). Only $4 \%$ of the vegetated area showed significant decrease trends, which were mostly in the central and southwestern plateau. A strong positive relationship between NDVI and precipitation, especially in the northeastern plateau, suggested that precipitation was a favorable factor for the grassland NDVI. Negative correlations between NDVI and temperature, especially in the southern plateau, indicated that higher temperature adversely affected the grassland growth. Although a warming climate was expected to be beneficial to the vegetation growth in cold regions, the grasslands in the central and southwestern plateau showed a decrease in trends influenced by increased temperature coupled with decreased precipitation. (C) The Authors. Published by SPIE under a Creative Commons Attribution 3.0 Unported License. Distribution or reproduction of this work in whole or in part requires full attribution of the original publication, including its DOI. [DOI: 10.1117/1.JRS.7.073572]
\end{abstract}

Keywords: Moderate Resolution Imaging Spectroradiometer; normalized difference vegetation index; partial correlation; trend analysis.

Paper 12375 received Oct. 31, 2012; revised manuscript received Mar. 19, 2013; accepted for publication Mar. 29, 2013; published online Apr. 25, 2013.

\section{Introduction}

The warming climate in recent decades has promoted vegetation growth in the northern hemisphere,,${ }^{1-8}$ such as Alaska, ${ }^{9,10}$ Canada,${ }^{11-13}$ and Russia. ${ }^{14,15}$ Global warming has also caused an increase in precipitation that resulted in vegetation greening in the southern hemisphere, such as African Sahel ${ }^{16-21}$ and South America, ${ }^{22}$ although some areas with a decrease in precipitation markedly reduced vegetation production. ${ }^{23,24}$ The Qinghai-Tibetan Plateau is regarded as a typical area for investigating the relationships between vegetation condition and climate variables, because the vegetation remains relatively undisturbed by human activities due to the low population and the plateau is dominated by alpine grasslands that appear to be highly sensitive to global climate change. The plateau has been experiencing a distinct warming trend in recent decades, and the warming is predicted to continue in the future. ${ }^{25-28}$ Climate records showed that the annual mean temperature in the Qinghai-Tibetan Plateau increased at a rate of $0.016^{\circ} \mathrm{C}$. $\mathrm{yr}^{-1}$ during 1955 to 1996 , which exceeds all other areas of the same latitude. ${ }^{5}$ With the last decade counted, the annual mean temperature increased by $1.8^{\circ} \mathrm{C}$ from 1960 to 2007 with an increase rate of $0.036^{\circ} \mathrm{C} \cdot \mathrm{yr}^{-1}$ (Ref. 28), which doubles the rate of the second half of 
the last century. However, the warming trend is spatially diverse in the plateau. ${ }^{26}$ Similarly, the precipitation showed different variations in different regions in the plateau. ${ }^{25}$ The joint influence of changing temperature and precipitation may result in complicated responses of the grasslands in the plateau.

Studies with Advanced Very High Resolution Radiometer (AVHRR) data ${ }^{29-34}$ and the SPOT VEGETATION (VGT) data ${ }^{35}$ indicated a general vegetation greening trend under climate warming in the plateau. Some regional studies with AVHRR and SPOT VGT data reported that climate change had stimulated vegetation growth in some areas of the plateau, such as parts of northern Tibet $^{36}$ and the Lake Yamzho Yumco Basin of southern Tibet. ${ }^{37}$ Using AVHRR and Moderate Resolution Imaging Spectroradiometer (MODIS) data, investigators found parts of the plateau experienced grassland degradation because of the drier and warmer climate. ${ }^{36,38}$ Besides climatic factors, human disturbance such as overgrazing and unreasonable use of grasslands also induced grassland degradation. ${ }^{39}$

Most previous investigations in the Qinghai-Tibetan Plateau employed the Global Inventory Modeling and Mapping Studies (GIMMS) AVHRR data. Because of incomplete or lack of atmospheric corrections of GIMMS AVHRR data, the trend analysis based on AVHRR data contains substantial uncertainties. ${ }^{40}$ Compared to AVHRR, MODIS land surface products, specifically designed to monitor terrestrial photosynthetic activity, have improved spectral, radiometric, and spatial characteristics. Therefore, MODIS data provides more consistent spatial and temporal comparisons of global and regional vegetation conditions. ${ }^{41}$ Although a few investigators have adopted MODIS data to analyze vegetation dynamics in the Qinghai-Tibetan Plateau, their studies were limited in small local areas. ${ }^{42}$

Studies have reported that grassland ecosystems in different regions in the world are fragile and sensitive to climate changes (e.g., Refs. 43-45). As a primary animal husbandry base in China, the Qinghai-Tibetan Plateau has very extensive grasslands covering 64\% of the vegetated area in the plateau. ${ }^{46}$ In this study, we investigated vegetation dynamics in the grasslands of the Qinghai-Tibetan Plateau in the past decade (2000 to 2009) using MODIS data. Specifically, our goals were to: (1) analyze the temporal trends and the spatial variations of grassland greenness and (2) evaluate the impact of climate changes on the vegetation greenness trends.

\section{Study Area and Data}

\subsection{Study Area}

In this study, the Qinghai-Tibetan Plateau $\left(26^{\circ} \mathrm{N}\right.$ to $40^{\circ} \mathrm{N}, 78^{\circ} \mathrm{E}$ to $\left.103^{\circ} \mathrm{E}\right)$ is referred to as the Qinghai Province and the Tibet Autonomous Region of China (Fig. 1). The climate in the plateau

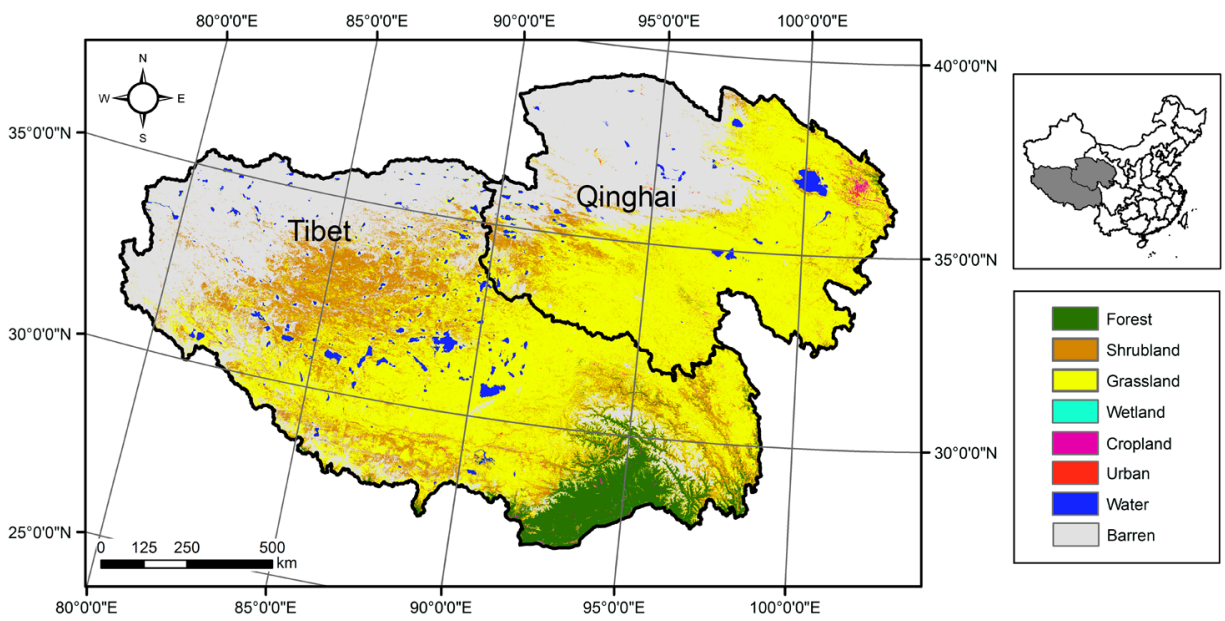

Fig. 1 Land cover types in the Qinghai-Tibetan Plateau simplified from the $500 \mathrm{~m}$ Moderate Resolution Imaging Spectroradiometer (MODIS) data (MCD12Q1). 
is characterized by strong solar radiation, low air temperature, and high day-night temperature difference. The annual mean temperature is below $0^{\circ} \mathrm{C}$ in most areas. The annual precipitation follows a gradient from over $1000 \mathrm{~mm}$ on the southeastern borders to less than $100 \mathrm{~mm}$ in the northwest. ${ }^{47}$ About $60 \%$ to $90 \%$ of the annual precipitation falls between June and September. ${ }^{33}$ Based on the $500 \mathrm{~m}$ MODIS global land cover data (MCD12Q1), ${ }^{48,49}$ the vegetation in the plateau includes grasslands $(70.4 \%)$, shrublands $(21.0 \%)$, forests $(7.8 \%)$, croplands $(0.7 \%)$, and wetlands $(0.1 \%)$. Grasslands are mainly in the cold and dry central and northwestern portions, and sparse shrubs exist in the north. Grasslands include alpine meadow, alpine steppe, and temperate steppe.

\subsection{Data}

In this study, we used the MODIS Surface Reflectance data (MOD09A1, collection 5) ${ }^{50}$ at an eight-day composite and $500 \mathrm{~m}$ resolution acquired from 2000 to 2009. The Quality Assurance layer was used to mask out cloud, shadow, and snow/ice pixels that were excluded in the data analysis. In our study, the MODIS normalized difference vegetation index (NDVI) was calculated to represent vegetation greenness. We identified vegetated land using the MCD12Q1 following the International Global Biosphere Programme global land cover classification scheme. The daily precipitation and temperature data were acquired from the China Meteorological Data Sharing Service System (Ref. 51). There are 46 weather stations (20 in Qinghai and 26 in Tibet) located in the grasslands/shrublands that have completed and continuous weather records from 2000 to 2009.

\section{Methods}

\subsection{Trend Analysis of NDVI Time Series}

We identified the regions with significant NDVI trend during 2000 to 2009 at inter- and intraannual (seasonal) levels. The snow season in the plateau normally begins mid-September to midOctober and ends April to late June of the next year. ${ }^{52}$ We calculated the growing-season NDVI in each year as the average of NDVI from May to September to avoid spurious snow contamination in April and October. The average of NDVI during the growing season was used as a proxy for seasonal vegetation productive in our study. Similarly, we calculated the growing-season temperature and precipitation that are the mean temperature and total precipitation of the growing season (May to September) in each year for each of the 46 weather stations. The seasonal NDVI was calculated as the mean NDVI values separately for late spring (May), summer (June to August), and early fall (September) for each year. The seasonal temperature and seasonal precipitation are the mean temperature and total precipitation of each season.

We identified the regions with significant inter- and intra-annual NDVI trends during 2000 to 2009 with a least squares linear regression method [Eq. (1)]:

$$
y(t)=a+b t+\varepsilon,
$$

where $y$ is the dependent variable representing the growing-season or seasonal NDVI, $t$ is the independent variable representing year, $b$ is the slope of the trend line, $a$ is the intercept, and $\varepsilon$ is the residual. We calculated the regression slope and the $p$-value for each pixel from the NDVI time series images. Thus, we obtained maps of inter- and intra-annual NDVI trends showing positive (increase trend) or negative (decrease trend) slope. To ensure the regression model was not impacted by potential temporal autocorrelations, we used the Durbin-Watson statistic ${ }^{53}$ to test the independency of the regression residuals. For the growing season NDVI values retrieved from 46 weather stations, only one site was found to have significant positive autocorrelation. Therefore, we consider that the temporal autocorrelation was not a serious issue in the trend analysis in the study area. 


\subsection{Correlation Analysis of NDVI and Climate Data}

To investigate the impact of climate on the NDVI trend, we applied the partial correlation analysis [Eq. (2)] for the growing-season NDVI and the climate variables (i.e., temperature and precipitation) at the 46 weather stations. Additionally, the correlation analysis was performed for the seasonal NDVI and climate variables in late spring, summer, and early fall at each site. We examined the correlation coefficients between seasonal NDVI and corresponding seasonal climate variables. The Pearson correlation coefficient $(r)$ is a measure of the correlation (linear dependence) between two variables $x$ and $y . y$ denotes the variable of NDVI in this study, $x$ denotes the variables of temperature and precipitation. At each grassland/shrubland weather station, the NDVI value was averaged spatially for a $3 \times 3$ pixel window centered at the station. Considering NDVI is affected by both temperature and precipitation, we used partial correlation analysis $^{53}$ [Eq. (2)] that involves investigating the relationship between NDVI and one climate variable after excluding the effect of another climate variable.

$$
r_{x y}=\frac{\sum x_{i} y_{i}-n \bar{x} \bar{y}}{(n-1) s_{x} s_{y}}=\frac{n \sum x_{i} y_{i}-\sum x_{i} \sum y_{i}}{\sqrt{n \sum x_{1}^{2}-\left(\sum x_{i}\right)^{2}} \sqrt{n \sum y_{i}^{2}-\left(\sum y_{i}\right)^{2}}},
$$

where $s_{x}$ and $s_{y}$ are the standard deviations of $x$ and $y$, respectively; $\bar{x}$ and $\bar{y}$ are the $x$ and $y$ mean values, respectively; and $n$ is the number of samples.

\section{Results}

\subsection{General Climate and Vegetation Trends from 2000 to 2009}

By averaging the climate data of all the 46 weather stations in the Qinghai-Tibetan Plateau [Fig. 2(a)], we found that the annual mean temperature showed a significant increase trend from 2000 to $2009(p$-value $<0.05)$ at a rate of $0.095^{\circ} \mathrm{C} \cdot \mathrm{yr}^{-1}$. The temperature in Tibet had a higher mean annual value $\left(5.15^{\circ} \mathrm{C}\right)$ and a higher increase rate $\left(0.115^{\circ} \mathrm{C} \cdot \mathrm{yr}^{-1}\right)$ than those in Qinghai $\left(2.45^{\circ} \mathrm{C} \cdot \mathrm{yr}^{-1}\right.$ and $0.074^{\circ} \mathrm{C} \cdot \mathrm{yr}^{-1}$, respectively). For the entire plateau, the spatially averaged annual total precipitation showed large temporal variations during the 10 years. Regionally, Qinghai had a significant positive trend $\left(10.7 \mathrm{~mm} \cdot \mathrm{yr}^{-1}\right)$ and Tibet had a significant negative trend $\left(-11.3 \mathrm{~mm} \cdot \mathrm{yr}^{-1}\right)$. Therefore, the climate from 2000 to 2009 became warmer and drier in Tibet but warmer and wetter in Qinghai.

\subsubsection{Inter-annual trend analysis}

Figure 2(b) displays the annual trends of the spatially averaged growing-season NDVI for all vegetation types of the entire Qinghai-Tibetan Plateau. The 2000 to 2009 NDVI trends increased significantly for most vegetation types with an average rate of $0.0036 \mathrm{yr}^{-1}$. Croplands had the largest positive slope $\left(0.0049 \mathrm{yr}^{-1}\right)$, followed by grasslands $\left(0.0030 \mathrm{yr}^{-1}\right)$, and shrublands with the lowest positive slope $\left(0.0014 \mathrm{yr}^{-1}\right)$. There was no significant NDVI trend with the forest class.

Most of the increase NDVI occurred in the northeast of the study area, especially in the Hainan Tibetan Semiarid Area $\left(R^{2}=0.64\right)$, the Naqu \& Golok Semihumid Area $\left(R^{2}=0.56\right)$, and the Ngawa Sichuan Humid Area $\left(R^{2}=0.65\right)$ (Figs. 3 and 4$)$. The significant positive trend ( $p$-value $<0.05)$ appeared in about $20 \%\left(210,000 \mathrm{~km}^{2}\right.$ ) of the vegetated area, which were located mainly in the semihumid and semiarid northeastern plateau. As shown in Fig. 3(b), the most increased areas (slope $>0.01 \mathrm{yr}^{-1}$ ) occurred in eastern Qinghai and limited areas of centraleastern Tibet (the East Tibetan Semi-humid Area), which accounted for $6.8 \%$ of the vegetated area of the plateau. Significant decrease trends ( $p$-value $<0.05$ ) appeared mostly in the southwestern and central plateau with only $4 \%\left(58,800 \mathrm{~km}^{2}\right)$ of the vegetated area, that was especially located in the Qiangtang semi-arid Area and the South Tibetan Semi-arid Area (Figs. 3 and 4). The areas with high decrease (slope $<-0.01 \mathrm{yr}^{-1}$ ) trend accounted for only $0.27 \%$ of the vegetated area. 

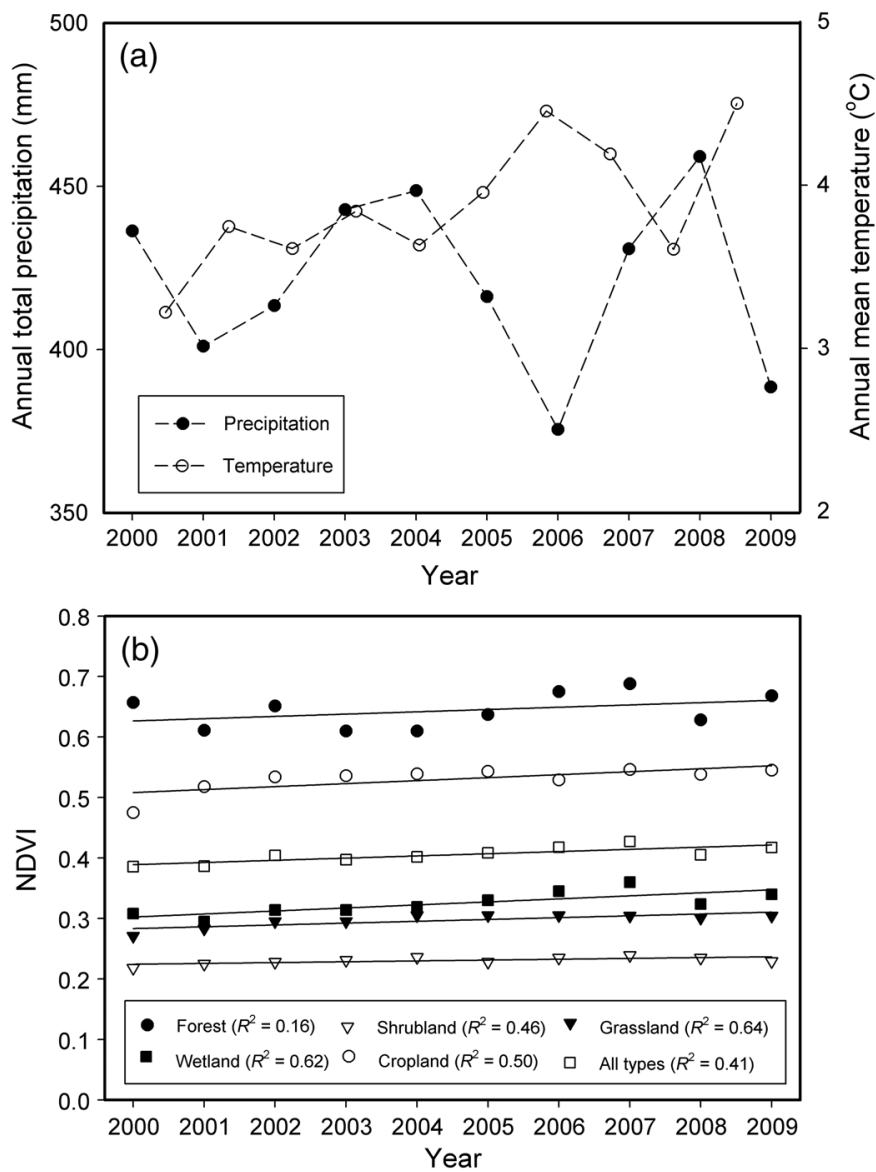

Fig. 2 (a) Trends of annual mean temperature and total precipitation and (b) spatially averaged growing-season normalized difference vegetation index (NDVI) for each vegetation type of the Qinghai-Tibetan Plateau during 2000 to 2009. The straight lines are the regression-derived trend lines.

\subsubsection{Seasonal trend analysis}

We divided the growing season into three seasons: spring (May), summer (June to August), and fall (September). The NDVI increase magnitude varied seasonally. Comparing fall, spring, and summer showed a large area having significant increase trends in the northeastern plateau (Fig. 5). The spatial patterns of the NDVI trends and the changing rates in spring and summer were similar to the entire growing season (May to September), but the slopes were steeper in spring and summer than in fall. Among the three seasons, spring had the largest area (about $15.4 \%$ of the vegetated area) of increase NDVI trend [Fig. 5(a)]. There were some areas of decrease trend in the three seasons in the southwestern and middle parts of the plateau, yet the decrease trend was not as extensive as the increase trend.

\subsection{Relationships Between NDVI and Climate Variables}

\subsubsection{Inter-annual analysis}

Figure 6 shows the spatial distributions of partial correlation coefficients $(r)$ between the growing-season NDVI and the two climate variables. The partial correlation between the growing-season NDVI and the growing-season temperature by controlling the growing-season precipitation showed negative relationships at most sites (31 over 46) [Fig. 6(a)]. Among all 46 sites, 13 sites showed significant negative correlations ( $p$-value $<0.1$ ), including 4 sites in Qinghai and 9 sites in Tibet. Compared to the northeastern plateau, the negative influence 


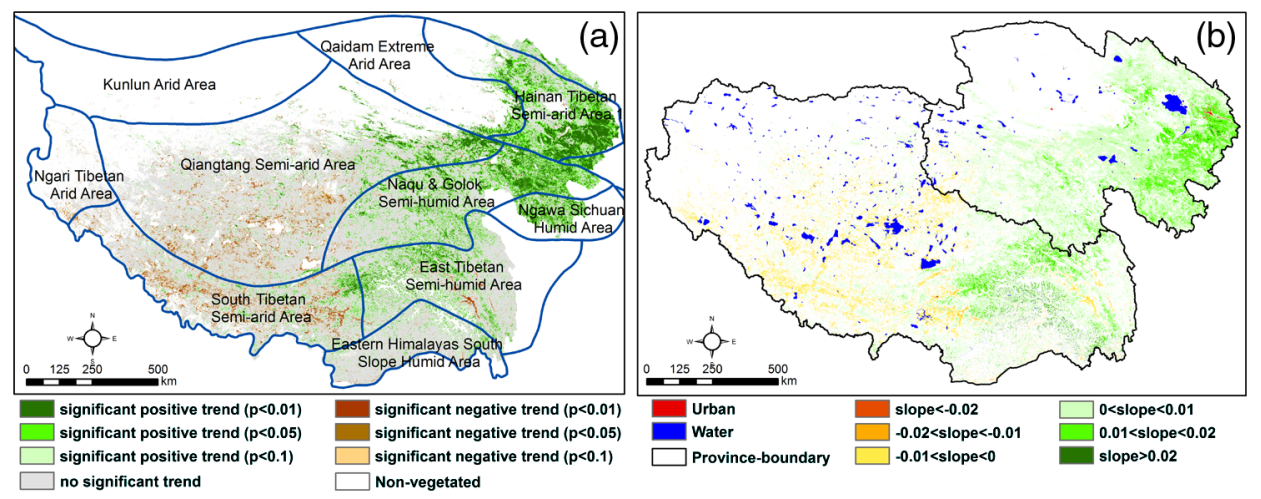

Fig. 3 Trends in the growing season NDVI during 2000 to 2009. (a) Vegetation greenness trend showing regression significance test and (b) regression slope with the slope of $p$-value $<0.05$. The polygons in (a) are the climate zones based on the Earth System Science Data Sharing Network (http://www.geodata.cn/).

of temperature on vegetation is stronger in the southern plateau, especially in the South Tibetan Semi-arid Area.

For the partial correlation by controlling the growing season temperature, the growingseason precipitation at most stations showed positive correlations with the growing-season NDVI [Fig. 6(b)]. There were 14 sites showing significant positive correlations ( $p$-value $<0.1)$ between NDVI and precipitation (11 sites in Qinghai and 3 sites in Tibet). Compared to the southern plateau, precipitation had a stronger positive influence $(r>0.6)$ on vegetation in the northeastern plateau (Qinghai), especially in the Hainan Tibetan semiarid area and the Naqu \& Golok semihumid area, where the vegetation had a noticeable increase trend. Negative correlation between NDVI and precipitation was also observed at several sites. In general, we noticed that the sites with high negative NDVI-temperature correlations were located mostly in the southern plateau, and the sites with high positive NDVI-precipitation correlations were located mostly in the northeastern plateau.

To further investigate the climatic impact on NDVI, we examined the stations with significant NDVI increase or decrease trends ( $p$-value <0.05) during the growing-season from 2000 to 2009 (Table 1). The 10-year NDVI time series showed significant trend ( $p$-value $<0.05$ ) only at 13 sites (Table 1) out of 46 climate stations. Most of these sites are located in the semiarid or arid areas, where vegetation is sensitive to precipitation. NDVI generally showed positive correlations with precipitation, but negative correlations with temperature. Significant warming was observed at many of these stations, particularly in Tibet, where NDVI exhibited negative trends.

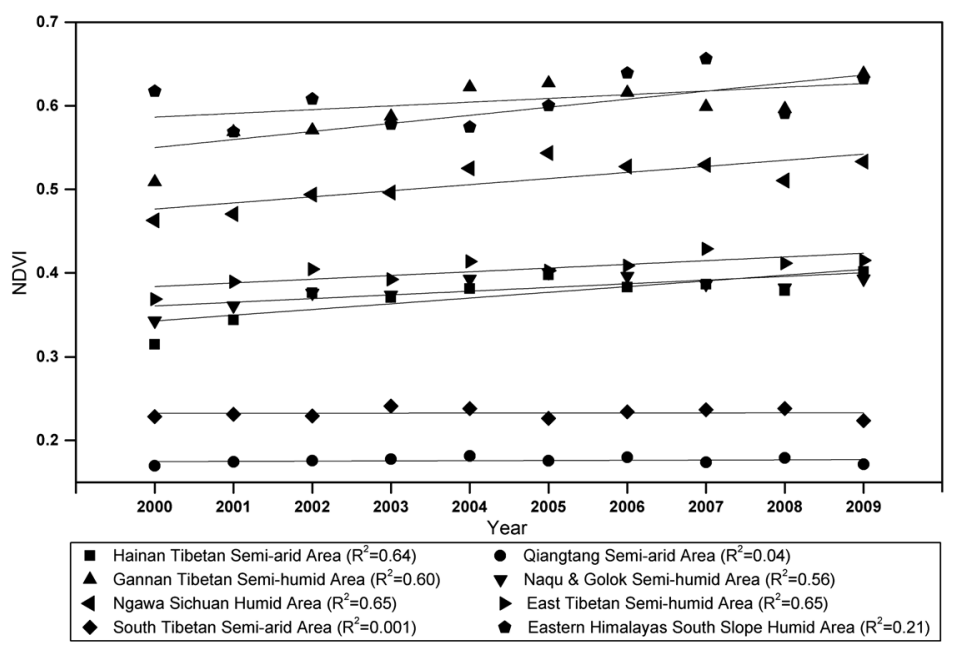

Fig. 4 Trends of the growing-season NDVI averaged spatially for each climate zone of the Qinghai-Tibetan Plateau during 2000 to 2009. The straight lines are the regression trend lines. 

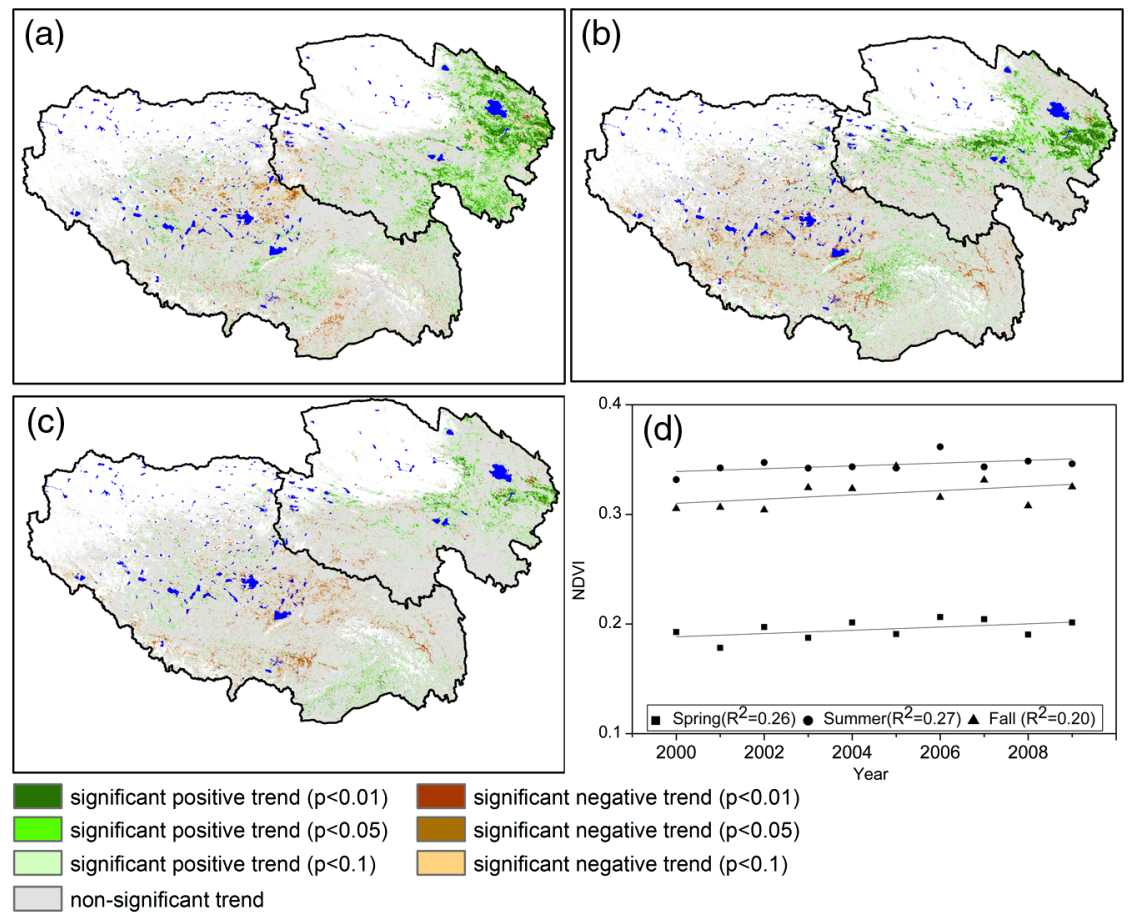

Fig. 5 NDVI trends during 2000 and 2009 in (a) spring, (b) summer, (c) fall, and (d) seasonal NDVI trends spatially averaged for the entire plateau.

We also noticed that the sites having the highest warming trends were also the sites that experienced the largest NDVI decrease (Table 1, e.g., Jiangzi, Mozhugongka, Rikeze, Dangxiong, Naqu, and Nangqian sites).

\subsubsection{Seasonal analysis}

We analyzed the relationships between NDVI and climate variables using the seasonal data sets. Figures 7 and 8 illustrate the correlation coefficients between NDVI and climate variables for the three seasons (spring, summer, and fall). The correlation coefficients between NDVI and temperature at 46 sites ranged from 0.69 to -0.48 in spring, 0.57 to -0.91 in summer, and 0.68 to -0.84 in fall (Fig. 7). The correlation coefficients between NDVI and temperature were higher with most sites existing negative correlations in summer and relatively weaker in spring. Similar to the correlations for the growing-season mean [Fig. 6(a)], the negative correlation between NDVI and temperature was identified for most sites in summer, especially significantly negative in the southern plateau (Tibet), such as the South Tibetan Semi-arid Area and the East Tibetan
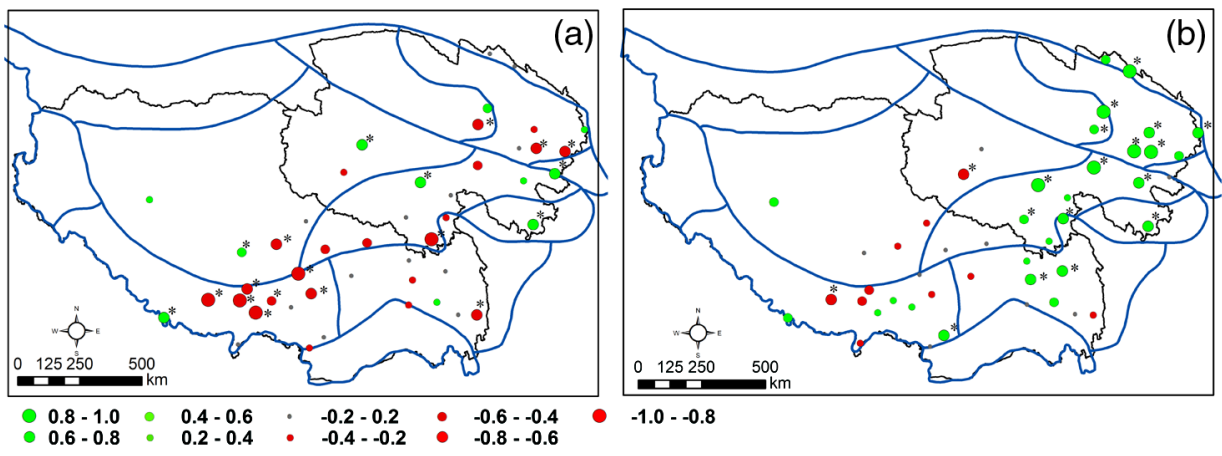

Fig. 6 (a) Partial correlation coefficients of growing-season NDVI versus growing-season temperature by controlling growing-season precipitation and (b) growing-season NDVI versus growingseason precipitation by controlling growing-season temperature at 46 grassland weather stations. Asterisks indicate significant correlation at $\alpha=0.1$ level. 
Zhang et al.: Vegetation greenness trend (2000 to 2009) and the climate controls...

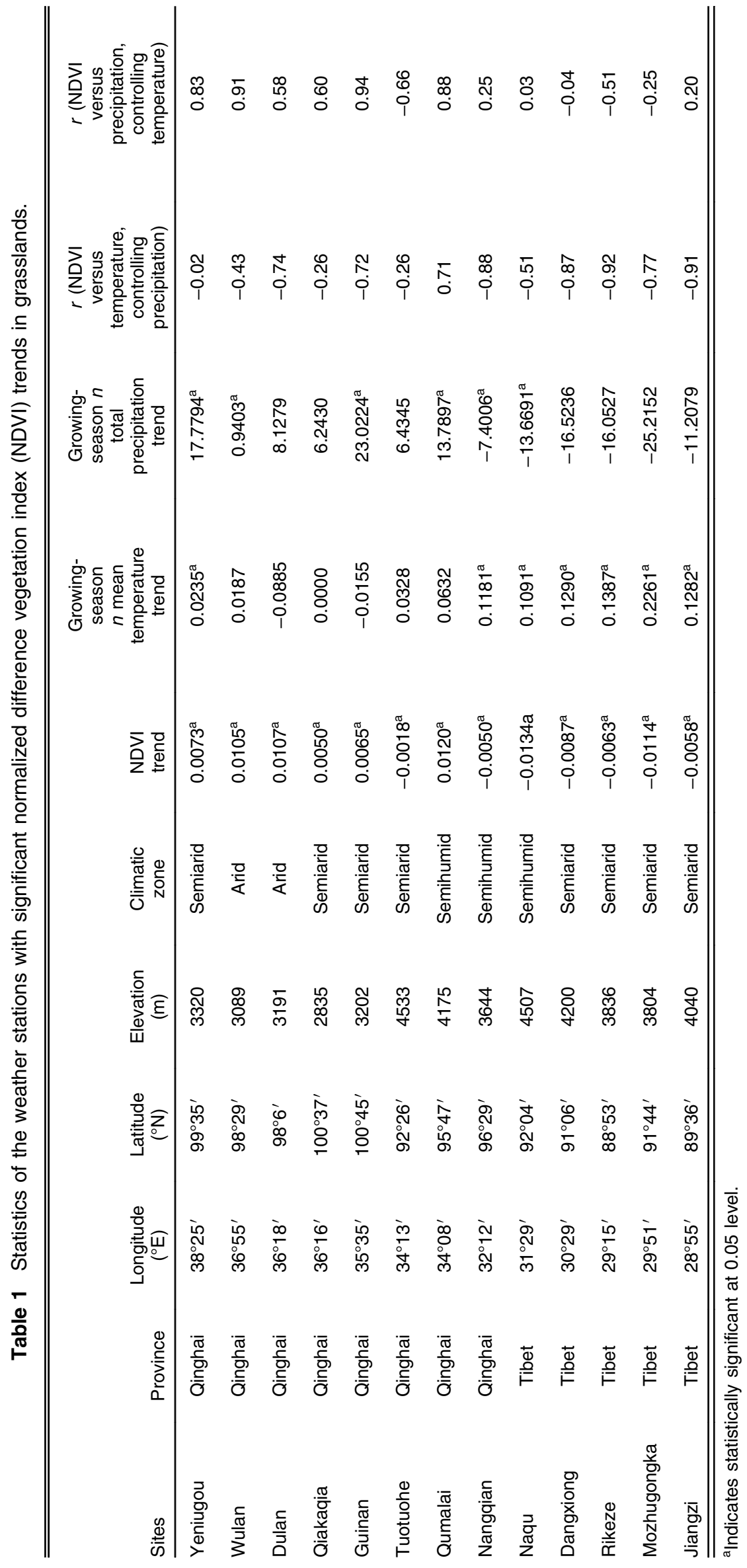




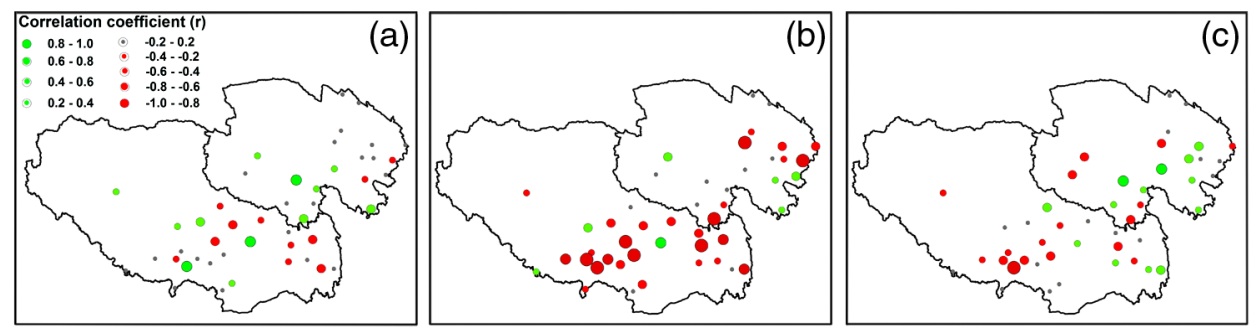

Fig. 7 Spatial distribution of correlation coefficients $(r)$ between NDVI and temperature during (a) spring, (b) summer, and (c) fall.

semi-humid Area, where the increased summer temperature reduced the NDVI. For fall, the increased temperature continued controlling the NDVI in the southern plateau, yet they switched to positive correlations in the northeastern plateau. Similar to the correlations for the growingseason mean [Fig. 6(b)], most of the sites presented the positive relationships between NDVI and precipitation in the three seasons (Fig. 8), which confirms that increased rainfall is likely the causative factor of increased NDVI. The correlation coefficient between NDVI and precipitation at 46 sites ranged from 0.82 to -0.86 in spring, 0.65 to -0.84 in summer, and 0.86 to -0.61 in fall. The positive effect of the rainfall on NDVI seemed stronger in spring and summer with a few sites showed negative correlations. In the three seasons, although a few sites showed negative correlations between NDVI and precipitation, most of the sites showed positive patterns. Increased precipitation promoted the vegetation growth in the northeastern plateau, but decreased precipitation restrained the vegetation growth in the southern plateau.

\section{Discussions}

The annual mean temperature over the plateau had increased at a rate of $0.095^{\circ} \mathrm{C} \cdot \mathrm{yr}^{-1}$ from 2000 to 2009 , which exceeds the rate of $0.016^{\circ} \mathrm{C} \cdot \mathrm{yr}^{-1}$ during 1955 to 1996 observed by Liu and Chen. ${ }^{26}$ The annual total precipitation showed large temporal variations during the 10 years for the entire plateau and varied among different spatial regions. Generally, the climate in Tibet became warmer and drier but warmer and wetter in Qinghai from 2000 to 2009.

\subsection{Vegetation Greenness Trends}

A significantly positive trend ( $p$-value $<0.05$ ) appeared in $20 \%$ of the vegetated area, which were located mainly in the semihumid and semiarid northeastern plateau. It seems that the increase trends had continued since the 1990s identified by Chen et al. ${ }^{54}$ who found that vegetation conditions in Maqu County in the northeastern plateau were better in the 1990s than those in the 1980s due primarily to increased precipitation. In the northeastern plateau (Qinghai), the increase in precipitation coupled with increased temperature may contribute to favorable conditions for vegetation growth, which was also verified by several studies in parts of northeastern plateau. $32,55,56$

By contrast, significant decrease trends appeared mostly in the southwestern and central plateau. Several previous studies ${ }^{31,54}$ also observed a decrease NDVI trend in the central plateau

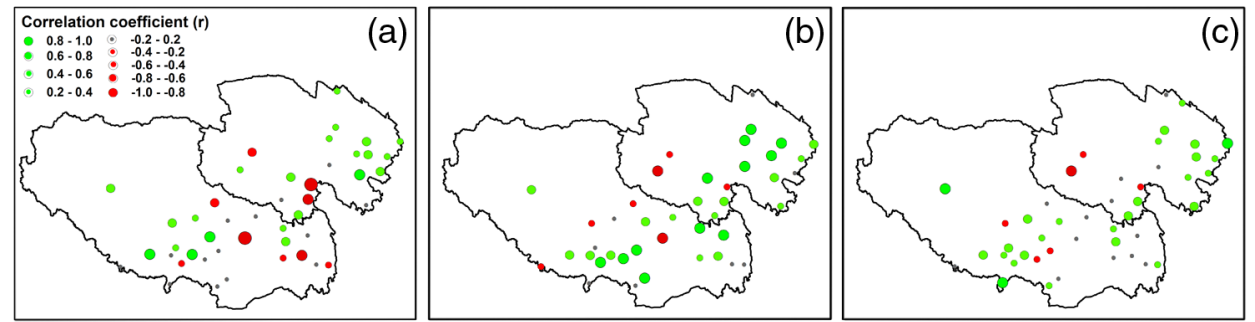

Fig. 8 Spatial distribution of correlation coefficients $(r)$ between NDVI and precipitation during (a) spring, (b) summer, and (c) fall. 
during 1982 and 2000. The negative relationship between temperature and NDVI over the plateau seems to contradict the general expectation that climate warming results in vegetation greening in the northern hemisphere. ${ }^{1-8,44,45}$ The drier and warmer climate in the central and southwestern plateau (Tibet) led to dry condition that aggravated the land degradation. Based on our analyses, the climate condition was unfavorable for vegetation growth in the central and southwestern plateau. Although increase temperature could prolong growing days and thus increase vegetation greenness, the warming climate may also increase evaporation and exacerbate the water demand for vegetation growth. As a result, vegetation condition deteriorates when regional precipitation decreases. Another possible reason is the shortening of the growing period with the late onset of the spring in the Tibetan Plateau..$^{57,58}$

The largest NDVI increase rate (slope $>0.01$ ) occurred in spring with more extensive and intensive increase trend, especially in the northeastern plateau, which could be partly explained by the advancement of the growing season and the speeding of the vegetation growth during the growing season. ${ }^{30}$ Therefore, the spring is an important season for vegetation greenness in the plateau.

\subsection{Climate Controls on Vegetation Greenness}

Because of relatively low population density and limited human activities in the central plateau, climate factors are deemed the dominant driving forces for the long-term vegetation conditions. Through altering the water balance and growing-season length, temperature and precipitation changes are considered the potential drivers for change in vegetation productivity. In our study, the vegetation in the Qinghai-Tibet Plateau was found to respond markedly to climate change with distinct differences in spatial and temporal domains (Fig. 6).

Generally, both precipitation and NDVI had increased trends in the northeastern plateau and decreased trends in the central and southwestern plateau. Based on our partial correlation analyses at weather stations that represented a wide range of NDVI and climatic variability, we found precipitation had a strong positive influence $(r>0.6)$ on vegetation in the northeastern plateau (Qinghai) where the vegetation had a noticeable increase trend. In Qinghai, plentiful rainfall provided moisture for vegetation growth in summer and thus helps reduce wind erosion. ${ }^{56}$ Our results also confirm the analysis by Ding et al. ${ }^{59}$ who stated that vegetation in Tibetan Plateau responded well to precipitation in the central and eastern plateau, but the responses were relatively weak in the western and southern plateau. However, our study also found negative correlation between NDVI and precipitation at several sites, especially at the sites in the southern plateau. Piao et al.$^{60}$ reported a similar phenomenon that increased snowfall and rainfall shortened the growing season, and thus reduced vegetation greenness in the cold and rainy regions of the plateau. These findings indicated that the vegetation conditions were relatively sensitive to precipitation in the northeastern plateau, but they were relatively sensitive to temperature in the southern plateau. In the relatively dry and warm southern plateau, the negative effects of water deficits outweighed the positive effects of higher temperature and solar radiation. ${ }^{61}$ Therefore, the concurrence of low precipitation and high temperature led to low moisture conditions, and thereby substantially reduced NDVI in the semiarid region.

The seasonality of the climate changes plays an important role in controlling seasonal vegetation greenness. For the entire area, the spring NDVI generally had positive correlations with temperature and precipitation. In summer, temperature had strong negative impacts on NDVI, yet precipitation had strong positive impacts on NDVI. Therefore, summer is the period when vegetation has the most sensitive responses to both temperature and precipitation in the plateau. The negative correlation between NDVI and temperature is especially strong in summer. Although higher temperature favors the grass growth in the alpine region in general, higher temperature in summer led to high evapotranspiration and soil moisture deficit in the semiarid region and thus restricted the vegetation growth. Water availability is another critical factor that regulates the vegetation growth in grasslands. ${ }^{45}$ The correlations between NDVI and precipitation was stronger in spring and summer (Fig. 8) when higher precipitation provided favorable conditions for the grassland during the growing season. Therefore, spring and summer may be the period when vegetation had the most sensitive responses to precipitation changes in this region. The high precipitation in the northeastern plateau increased NDVI in summer, but 
the low precipitation in the southern plateau (Tibet) caused poorer vegetation conditions. The warmer and drier conditions in the southern plateau suppressed the vegetation growth, especially in summer. Figures 7 and 8 imply that the temperature and precipitation played a significant role in NDVI magnitude for three seasons. Compared with the seasonal analysis (Figs. 7 and 8), the analysis for growing-season mean (Fig. 6) integrated the cumulative effects of climate on NDVI during the three seasons. Therefore, we need fully consider both inter-annual and inter-seasonal analysis for future applications, which would explain the vegetation changes under different time frames and conditions.

\subsection{Other Factors Impacting on Vegetation Greenness}

As we discussed above, climatic change was one of the important factors influencing the vegetation greenness in the plateau. However, the climate impacts on grasslands of the QinghaiTibetan Plateau may be more complicated than we investigated in this study and the vegetation greenness trends cannot fully be explained by temperature and precipitation. The impacts from human activities might profoundly affect the vegetation. The NDVI increase in some areas may be due to the implementation of a series of national policies for grassland protection and construction, such as the "Grain for Green" program implemented throughout China since 1999, ${ }^{62}$ China's revised Grassland Law (2003), and an ecological restoration project since 2005 that enforced restricting livestock numbers and decreasing grazing intensity. ${ }^{34}$ The "Grain for Green" program encourages converting cropland to grassland or forest, converting pasture to grassland, and converting reclaimed grasslands to grasslands, which stimulated a significant increase in farmland vegetation cover in the northern part of the Yellow River basin. ${ }^{62}$ The China's revised Grassland Law (2003) further strengthened the legal protection in grassland environment.

Beyond the national policy, other human activities, such as overstocking of livestock, poor livestock management, and excessive soil disturbance from small mammals, may also cause the grassland degradation. The rodent's intense activities exacerbated the grassland degradation in the plateau ${ }^{63}$ and their damages mainly depended on the population densities ${ }^{64}$ and precipitation conditions. ${ }^{65}$ The increased temperature also caused thawing of permafrost, and thus increased soil temperature and reduced soil moisture ${ }^{66}$ and aggravated the degradation of grassland. Therefore, the relative importance of the climatic and human-induced factors may vary in different regions.

\section{Conclusions}

We analyzed the NDVI trends during 2000 to 2009 and their responses to temperature and precipitation in the Qinghai-Tibetan Plateau using MODIS data and extensive weather station data. The NDVI showed an increase trend in about $20 \%$ of the vegetated area and a decrease trend for only $4 \%$ of the vegetated area. Significant positive trends mainly occurred in the northeastern plateau and significant decrease trends were mainly distributed in the southwestern and central plateau.

Both precipitation and temperature are dominant climate factors contributing to the grassland growth in the Qinghai-Tibet Plateau. The partial correlation analysis at the weather stations with significant NDVI trends indicated that the NDVI was strongly related to temperature and precipitation at most sites. Generally, precipitation showed strong and positive impact on vegetation greenness in the northeastern plateau, while temperature had a significant negative impact in the southern plateau where precipitation is more limited in this area. The warmer and drier conditions in the southern plateau reduced the vegetation growth, and the warmer and wet condition in the northeastern plateau promoted vegetation growth. Vegetation responded to climate changes differently in three seasons. Generally, temperature had stronger negative impacts on NDVI in summer than other seasons, yet the precipitation had stronger positive impacts on NDVI in spring and summer than fall. Our study specified the spatial heterogeneities in climate and vegetation growth patterns in this climate-sensitive highland, which may improve our understanding of global climate change and vegetation responses in alpine grassland ecosystems. 
Our analysis had two limitations that should be considered for future analysis. First, over the Qinghai-Tibetan Plateau, snow usually starts around mid-September to mid-October and ends around April to late June of the next year. ${ }^{36,55}$ Therefore, NDVI of the growing season, especially in May and September, may be contaminated by snow in some years. Our analysis may be affected by the snow contaminations although we have excluded the cloud, shadow, and snow/ice pixels based on the quality assurance layer provided by the MODIS data, through which we expected to minimize the impact from the snow contaminations. Second, the change in the growing season lengths would make a difference in the amplitude and the trend of interannual changes of vegetation. The climate variables (i.e., temperature and precipitation) were proven to affect phenology (e.g., green-up onset) in grasslands of the Qinghai-Tibetan Plateau. ${ }^{67}$ In the frigid plateau, grassland begins to green up at a certain cumulative temperature. Snowfall in spring also cause a delay in the start of the growing season and reduce the peak greenness. ${ }^{12}$ Additionally, in the arid and semiarid grasslands, water condition is another environmental factor affecting phenology. Delayed spring phenology had been monitored by $\mathrm{Yu}$ et al. ${ }^{57}$ and Chen et al. ${ }^{58}$ in the plateau. Therefore, the different climate conditions through the years would impact the vegetation phenology in different years, which may impact the values of the averaged growing-season NDVI and thus the amplitude and inter-annual trend of the vegetation. Future remote sensing studies of vegetation changes can be strengthened with the analysis considering the phonological effects.

\section{Acknowledgments}

The study was supported by the National Basic Research Program of China (973) (Grant No. 2009CB723906) and the National Natural Science Foundation of China (Grant No. 41271372). The work by Lei Ji was performed under USGS contract G08PC91508.

\section{References}

1. R. B. Myneni, C. D. Keeling, and C. J. Tucker, "Increased plant growth in the northern high latitudes from 1981 to 1991," Nature 386(6626), 698-702 (1997), http://dx.doi.org/ $10.1038 / 386698 \mathrm{a} 0$.

2. L. Zhou et al., "Variations in northern vegetation activity inferred from satellite data of vegetation index during 1981 to 1999," J. Geophy. Res. 106(D17), 20069-20083 (2001), http://dx.doi.org/10.1029/2000JD000115.

3. W. Lucht et al., "Climatic control of the high-latitude vegetation greening trend and Pinatubo effect," Science 296(5573), 1687-1689 (2002), http://dx.doi.org/10.1126/ science. 1071828.

4. D. A. Slayback et al., "Northern hemisphere photosynthetic trends 1982-99," Glob. Change Biol. 9(1), 1-15 (2003), http://dx.doi.org/10.1046/j.1365-2486.2003.00507.x.

5. R. R. Nemani et al., "Climate-driven increases in global terrestrial net primary production from 1982 to 1999," Science 300(5625), 1560-1563 (2003), http://dx.doi.org/10.1126/ science. 1082750.

6. S. S. Young and R. Harris, "Changing patterns of global-scale vegetation photosynthesis, 1982-1999," Int. J. Rem. Sens. 26(20), 4537-4563 (2005), http://dx.doi.org/10.1080/ 01431160500239198.

7. S. Piao, J. Fang, and J. He, "Variations in vegetation net primary production in the QinghaiXizang Plateau, China, from 1982 to 1999," Clim. Change 74(1-3), 253-267 (2006), http:// dx.doi.org/10.1007/s10584-005-6339-8.

8. P. S. A. Beck and S. J. Goetz, "Satellite observations of high northern latitude vegetation productivity changes between 1982 and 2008: ecological variability and regional differences," Environ. Res. Lett. 7(2), 029501 (2012), http://dx.doi.org/10.1088/17489326/7/2/029501.

9. D. Stow et al., "Greenness trends of Arctic tundra vegetation in the 1990s: comparison of two NDVI data sets from NOAA AVHRR systems," Int. J. Rem. Sens. 28(21), 4807-4822 (2007), http://dx.doi.org/10.1080/01431160701264284. 
10. G. J. Jia, H. E. Epstein, and D. A. Walker, "Vegetation greening in the Canadian arctic related to decadal warming," J. Environ. Monit. 11(12), 2231-2238 (2009), http://dx.doi .org/10.1039/b911677j.

11. I. Olthof et al., "Recent (1986-2006) vegetation-specific NDVI trends in Northern Canada from satellite data," Arct. Inst. North Am. 61(4), 381-394 (2008).

12. D. Pouliot, R. Latifovic, and I. Olthof, "Trends in vegetation NDVI from $1 \mathrm{~km}$ AVHRR data over Canada for the period 1985-2006," Int. J. Rem. Sens. 30(1), 149-168 (2009), http:// dx.doi.org/10.1080/01431160802302090.

13. G. B. Hill and G. R. Henry, "Responses of high Arctic wet sedge tundra to climate warming since 1980," Glob. Change Biol. 17(1), 267-287 (2011), http://dx.doi.org/10.1111/gcb .2010.17.issue-1.

14. D. A. Walker et al., "Spatial and temporal patterns of greenness on the Yamal Peninsula, Russia: interactions of ecological and social factors affecting the Arctic normalized difference vegetation index,' Environ. Res. Lett. 4(4), 045004 (2009), http://dx.doi.org/10.1088/ 1748-9326/4/4/045004.

15. B. C. Forbes, M. M. Fauria, and P. Zetterberg, "Russian Arctic warming and 'greening' are closely tracked by tundra shrub willows," Glob. Change Biol. 16(5), 1542-1554 (2010), http://dx.doi.org/10.1111/gcb.2010.16.issue-5.

16. L. Eklundh and L. Olsson, "Vegetation index trends for the African Sahel 1982-1999," Geophys. Res. Lett. 30(8), 1430 (2003), http://dx.doi.org/10.1029/2002GL016772.

17. A. Anyamba and C. J. Tucker, "Analysis of Sahelian vegetation dynamics using NOAAAVHRR NDVI data from 1981-2003," J. Arid Environ. 63(3), 596-614 (2005), http:// dx.doi.org/10.1016/j.jaridenv.2005.03.007.

18. S. M. Herrmann, A. Anyamb, and C. J. Tucker, "Recent trends in vegetation dynamics in the African Sahel and their relationship to climate," Glob. Environ. Change 15(4), 394-404 (2005), http://dx.doi.org/10.1016/j.gloenvcha.2005.08.004.

19. N. Martiny, Y. Richard, and P. Camberlin, "Interannual persistence effects in vegetation dynamics of semi-arid Africa," Geophys. Res. Lett. 32(24), L24403 (2005), http://dx.doi .org/10.1029/2005GL024634.

20. L. Olsson, L. Eklundh, and J. Ardo, "A recent greening of the Sahel-trends, patterns and potential causes," J. Arid Environ. 63(3), 556-566 (2005), http://dx.doi.org/10.1016/j .jaridenv.2005.03.008.

21. V. Capecchi et al., "Analysis of NDVI trends and their climatic origin in the Sahel 1986-2000," Geocarto Int. 23(4), 297-310 (2008), http://dx.doi.org/10.1080/10106040801950492.

22. J. M. Paruelo et al., "Temporal and spatial patterns of ecosystem functioning in protected arid areas in southeastern Spain,” Appl. Veg. Sci. 8(1), 93-102 (2005), http://dx.doi.org/ 10.1111/j.1654-109X.2005.tb00633.x.

23. A. Kawabata, K. Ichii, and Y. Yamaguchi, "Global monitoring of interannual changes in vegetation activities using NDVI and its relationships to temperature and precipitation," Rem. Sens. 22(7), 1377-1382 (2001), http://dx.doi.org/10.1080/01431160119381.

24. R. J. Donohue, T. R. Mcvicar, and M. L. Roderick, "Climate-related trends in Australian vegetation cover as inferred from satellite observations, 1981-2006," Glob. Change Biol. 15(4), 1025-1039 (2009), http://dx.doi.org/10.1111/gcb.2009.15.issue-4.

25. Z. Lin and X. Zhao, "Spatial characteristics of changes in temperature and precipitation of the Qinghai-Xizang (Tibet) Plateau," Sci. China Ser. D Earth Sci. 26, 254-258 (1996).

26. X. Liu and B. Chen, "Climatic warming in the Tibetan Plateau during recent decades," Int. J. Climatol. 20(14), 1729-1742 (2000), http://dx.doi.org/10.1002/(ISSN)1097-0088.

27. X. Liu et al., "Temporal trends and variability of daily maximum and minimum extreme temperature events, and growing season length over the eastern and central Tibetan Plateau during 1961-2003," J. Geophys. Res. 111(D19), 10901-10919 (2006), http://dx.doi.org/ 10.1029/2005JD006915.

28. B. Wang et al., "Tibetan Plateau warming and precipitation change in East Asia," Geophys. Res. Lett. 35(14), L14702 (2008), http://dx.doi.org/10.1029/2008GL034330.

29. Y. Hou, J. Zhang, and Y. He, "Intra-and inter-annual variation patterns of NDVI in Tibet based on AVHRR remote sensing data," Chin. J. Ecol. 24(11), 1273-1276 (2005) (In Chinese). 
30. Y. Yang and S. Piao, "Variations in grassland vegetation cover in relation to climatic factors on the Tibetean Plateau," J. Plant Ecol. 30(1), 1-8 (2006) (In Chinese).

31. S. Liang et al., "Regularity of vegetation coverage changes in the Tibetan Plateau over the last 21 years," Adv. Earth Sci. 22(1), 33-40 (2007) (In Chinese).

32. W. Xu and X. Liu, "Response of vegetation in the Qinghai-Tibet plate to global warming," Chin. Geogr. Sci. 17(2), 151-159 (2007), http://dx.doi.org/10.1007/s11769-007-0151-5.

33. Z. X. Xu, T. L. Gong, and J. Y. Li, "Decadal trend of climate in the Tibetan Plateau-regional temperature and precipitation," Hydrol. Process. 22(16), 3056-3065 (2008), http://dx.doi .org/10.1002/hyp.v22:16.

34. W. Xu et al., "High positive correlation between soil temperature and NDVI from 1982 to 2006 in alpine meadow of the Three-River Source Region on the Qinghai-Tibetan Plateau," Int. J. Appl. Earth Obs. Geoinf. 13(4), 528-535 (2011), http://dx.doi.org/10.1016/j.jag.2011 .02 .001 .

35. L. Zhong et al., "Assessment of vegetation dynamics and their response to variations in precipitation and temperature in the Tibetan Plateau," Clim. Change 103(3-4), 519-535 (2010), http://dx.doi.org/10.1007/s10584-009-9787-8.

36. J. Zhang et al., "Evaluation of grassland dynamics in the Northern-Tibet Plateau of China using remote sensing and climate data," Sensors 7(12), 3312-3328 (2007), http://dx.doi.org/ 10.3390/s7123312.

37. S. Yu, J. Liu, and J. Yuan, "Vegetation change of Yamzho Yumco Basin in southern Tibet based on SPOT-VGT NDVI,” Spectrosc. Spectral Anal. 30(6), 1570-1574 (2010) (In Chinese).

38. J. Yang, Y. Ding, and R. Chen, "NDVI reflection of alpine vegetation in the source regions of the Yangtze, and Yellow Rivers," Acta Geogr. Sin. 60(3), 467-478 (2005) (In Chinese).

39. Q. Gao et al., Remote Sensing Monitoring of Grassland Degradation, and Eco-Functional Regionalization in Northern Tibet, Climatic Press, Beijing (2006) (In Chinese).

40. J. R. Nagol, E. F. Vermote, and S. D. Prince, "Effects of atmospheric variation on AVHRR NDVI data," Rem. Sens. Environ. 113(2), 392-397 (2009), http://dx.doi.org/10.1016/j.rse 2008.10.007.

41. C. O. Justice et al, "The Moderate Resolution Imaging Spectroradiometer (MODIS): land remote sensing for global change research," IEEE Trans. Geosci. Rem. Sens. 36(4), 1228-1249 (1998), http://dx.doi.org/10.1109/36.701075.

42. Y. Zhu et al., "Temporal, and spatial changes of vegetation in Linzhi area based on MODISNDVI," Geogr. Geo-Inf. Sci. 26(5), 58-62 (2010) (In Chinese).

43. L. Yang et al., "An analysis of relationships among climate forcing and time-integrated NDVI of grasslands over the U.S. Northern and Central Great Plains," Rem. Sens. Environ. 65(1), 25-37 (1998), http://dx.doi.org/10.1016/S0034-4257(98)00012-1.

44. E. S. Zavaleta et al., "Grassland responses to three years of elevated temperature, $\mathrm{CO}_{2}$, precipitation, and $N$ deposition," Ecol. Monogr. 73(4), 585-604 (2003), http://dx.doi .org/10.1890/02-4053.

45. L. Ji and A. J. Peters, "A spatial regression procedure for evaluating the relationship between AVHRR-NDVI and climate in the northern Great Plains," Int. J. Rem. Sens. 25(2), 297-311 (2004), http://dx.doi.org/10.1080/0143116031000102548.

46. China Vegetation Atlas Editorial Committee of the Chinese Academy of Sciences, "Atlas China Vegetation (1: 1000000)," Science Press, Beijing (2001) (In Chinese).

47. S. Q. Zhao, Geography of China: Environment, Resources, Population and Development, Wiley, New York (1994).

48. M. A. Friedl et al., "Global land cover mapping from MODIS: algorithms and early results," Rem. Sens. Environ. 83(1-2), 287-302 (2002), http://dx.doi.org/10.1016/S0034-4257(02) 00078-0.

49. M. A. Friedl et al., "MODIS collection 5 global land cover: algorithm refinements and characterization of new datasets," Rem. Sens. Environ. 114(1), 168-182 (2010), http:// dx.doi.org/10.1016/j.rse.2009.08.016.

50. E. F. Vermote, N. El Saleous, and C. O. Justice, "Atmospheric correction of MODIS data in the visible to middle infrared: first results," Rem. Sens. Environ. 83(1-2), 97-111 (2002), http://dx.doi.org/10.1016/S0034-4257(02)00089-5. 
51. "Observed meteorological data," China Meteorological Data Sharing Service System, http:// cdc.cma.gov.cn.

52. D. H. Qin, S. Y. Liu, and P. J. Li, "Snow cover distribution, variability, and response to climate change in Western China," J. Clim. 19(9), 1820-1833 (2006), http://dx.doi.org/ 10.1175/JCLI3694.1.

53. J. Neter, W. Wasserman, and M. H. Kutner, Applied Linear Statistical Models: Regression, Analysis of Variance, and Experimental Designs, IRWIN, Burr Ridge, Illinois (1990).

54. J. Chen et al., "A tentative discussion on the trend of ecological environment change in Qinghai-Tibet Plateau," Acta Gesci. Sin. 28(6), 555-560 (2007) (In Chinese).

55. L. Wang, Y. Wei, and Z. Niu, "Spatial and temporal variations of vegetation in Qinghai Province based on satellite data," J. Geogr. Sci. 18(1), 73-84 (2008), http://dx.doi.org/ 10.1007/s11442-008-0073-x.

56. C. Y. Miao et al., "The vegetation cover dynamics (1982-2006) in different erosion regions of the Yellow River basin, China," Land Degrad. Dev. 23, 62-71 (2012), http://dx.doi.org/ 10.1002/ldr.v23.1.

57. H. Yu, E. Luedeling, and J. Xu, "Winter and spring warming result in delayed spring phenology on the Tibetan Plateau," Proc. Natl. Acad. Sci. U.S.A. 107(51), 22151-22156 (2010), http://dx.doi.org/10.1073/pnas.1012490107.

58. H. Chen et al., "Delayed spring phenology on the Tibetan Plateau may also be attributable to other factors than winter and spring warming," Proc. Natl. Acad. Sci. U.S.A. 108(19), E93 (2011), http://dx.doi.org/10.1073/pnas.1100091108.

59. M. Ding et al., "The relationship between NDVI and precipitation on the Tibetan Plateau," J. Geogr. Sci. 17(3), 259-268 (2007), http://dx.doi.org/10.1007/s11442-007-0259-7.

60. S. Piao et al., "Interannual variations of monthly and seasonal normalized difference vegetation index (NDVI) in China from 1982 to 1999," J. Geophys. Res. 108(D14), 4401 (2003), http://dx.doi.org/10.1029/2002JD002848.

61. J. F. Xiao et al., "Twentieth-century droughts and their impacts on terrestrial carbon cycling in China," Earth Interact. 13(10), 1 (2009), http://dx.doi.org/10.1175/2009EI275.1.

62. H. J. Zhou, A. V. Rompaey, and J. A. Wang, "Detecting the impact of the "Grain for Green" program on the mean annual vegetation cover in the Shaanxi province, China using SPOTVGT NDVI data," Land Use Pol. 26(4), 954-960 (2009), http://dx.doi.org/10.1016/j .landusepol.2008.11.006.

63. H.-L. Lin, Z.-Q. Wang, and Z.-H. Shang, "Features on fractal dimension of barren patch, and mouse hole among different degenerated succession stages on alpine meadow in the source region of the Yangtze, and Yellow River, Qinghai Tibetan Plateau, China," Acta Agrestia Sin. 18, 477-484 (2010) (In Chinese).

64. Q.-H. Cui et al., "A review of the cause of rangeland degradation on Qinghai Tibet Plateau," Pratacult. Sci. 26, 20-26 (2007) (In Chinese).

65. M. L. Xia et al., "Dynamics of rodents. Holes on alpine meadow in Tibet Shigatse," Pratacult. Sci. 28, 449-453 (2011) (In Chinese).

66. Q. Zhuang et al., "Carbon dynamics of terrestrial ecosystems on the Tibetan Plateau during the 20th century: an analysis with a process-based biogeochemical model," Glob. Ecol. Biogeogr. 19(5), 649-662 (2010), http://dx.doi.org/10.1111/j.1466-8238.2010.00559.x.

67. M. Shen et al., "Influences of temperature and precipitation before the growing season on spring phenology in grasslands of the central and eastern Qinghai-Tibetan Plateau," Agric. For. Meteorol. 151(12), 1711-1722 (2011), http://dx.doi.org/10.1016/j.agrformet.2011.07.003.

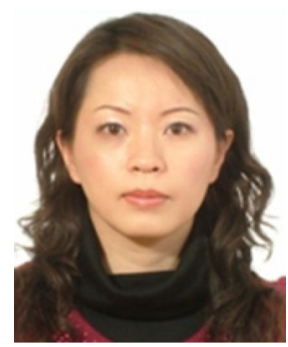

Li Zhang is an associate professor at the Institute of Remote Sensing and Digital Earth, CAS. She received a BS degree from Wuhan Technical University of Surveying and Mapping, China, in 1998, and a MS degree in geography from South Dakota State University, USA, in 2005. From 1998 to 2003, she worked at the Chinese Academy of Surveying and Mapping, China, involved in remote sensing monitoring of urban and water resources. From 2005 to 2008, she was an environmental scientist with the Science Applications International Corp. (SAIC), contractor to the United States Geological Survey, Earth Resources Observation and 
Science (EROS) Center working on carbon modeling, ecosystem performance, and soil moisture-vegetation relationships. Her research interest includes application of remote sensing, spatial analysis of ecosystem and land surface dynamics, and carbon cycling.

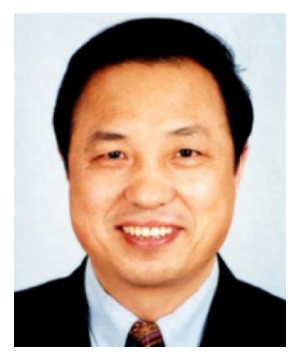

Huadong Guo is the director general and professor at the Institute of Remote Sensing and Digital Earth, Chinese Academy of Sciences(CAS), he has been engaged in remote sensing research since 1977, devoting to research on radar remote sensing, development of new earth observing systems, and remote sensing applications. He was project leader of more than 10 key programs related to earth observation. For more than 10 years, he has been one of the principal investigators for SIR-C/X-SAR, JERS-1 SAR, ERS-1/2 SAR, Radarsat-1/2, Envisat, SRTM, and ALOS programs. $\mathrm{He}$ is a member of International SAR Working Group, chairman of the Association on Environment Remote Sensing of China, secretary general of International Society for Digital Earth, editor-in-chief of International Journal of Digital Earth, member of Codata executive committee, and guest professor of seven universities in China.

Lei $\mathbf{J i}$ is an environmental scientist at the Earth Resources Observation and Science (EROS) Center a contractor to the U.S. Geological Survey (USGS). His research interest includes remote sensing of land surface characteristics and processes; evaluation of spectral vegetation, soil, and water indices; modeling of land-surface spectral responses to climatic and environmental changes; time series analysis of remotely sensed images; and spatial statistics and spatial pattern analysis.

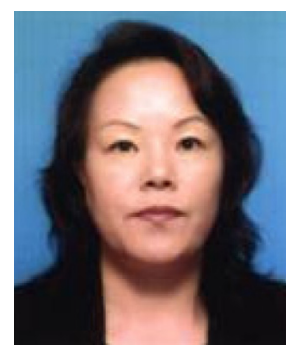

Liping Lei is a research scientist at the Institute of Remote Sensing and Digital Earth, Chinese Academy of Sciences (CAS). She received BS and MS degrees in physical geography and remote sensing from the Peking University, China, in 1983 and 1986, respectively, and a $\mathrm{PhD}$ degree in computer information system from the Iwate University, Japan, in 1999. She is the author of more than 45 journal papers. Her current research interests include remote sensing applications, global change and image processing systems.

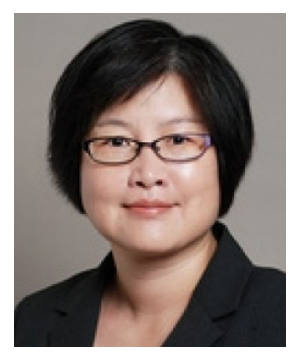

Cuizhen Wang received the BS degree from the Shandong University of Science and Technology, China, in 1993, MA and PhD degrees from the Institute of Remote Sensing Applications, Chinese Academy of Sciences, Beijing, China, in 1996 and 1999, and the PhD degree from Michigan State University, East Lansing, in 2004. She is currently an associate processor with the Department of Geography, University of Missouri, Columbia, with research expertise in bio-environmental remote sensing and spatial analysis.

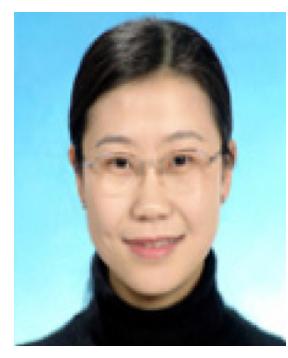

Dongmei Yan is a professor at the Institute of Remote Sensing and Digital Earth, Chinese Academy of Sciences (CAS). She received a PhD degree from the Institute of Remote Sensing Applications, Chinese Academy of Sciences, China, in 2004. She is involved in remote sensing image processing, remote sensing image information extraction, image interpreting, and computer vision. 


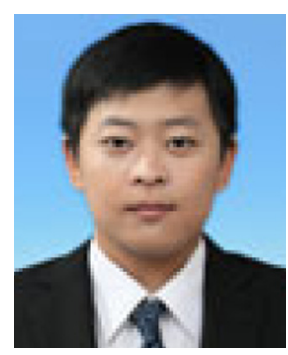

Bin $\mathbf{L i}$ is an engineer in the Technology and Engineering Center for Space Utilization, Chinese Academy of Sciences. He received bachelor's and master's degrees from Shandong Agricultural University, China. His research interest includes mapping and remote sensing applications, global changes, and disaster monitoring and analyzing.

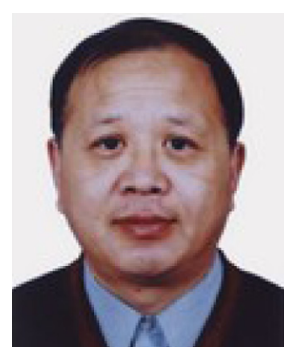

Jing $\mathbf{L i}$ received the BS degree in geography and the MS degree in graphics and remote sensing from Peking University, Beijing, China, in 1982 and 1985, respectively. He is currently a professor of the Beijing Normal University, Beijing. From 1993 to 2003, he was with the Institute of Remote Sensing and Geographical Information Systems, Peking University. Since 2003, he has been a professor with Beijing Normal University and the chief engineer of the National Disaster Reduction Committee, Ministry of Civil Affairs of China. His research interests include remote sensing applications in natural disaster reduction and remote sensing monitoring of oceanic and coastal ecology and natural resources. 